\title{
El pluralismo teológico, condición para el diálogo intra- y extraeclesial
}

\author{
José Antonio Revuelta C.*
}

\author{
Recibido: Julio 2011 • Aceptado: Setiembre 2011
}

\section{RESUMEN}

En este ensayo se plantea la necesidad del pluralismo teológico como condición para el diálogo dentro y fuera de la Iglesia Católica. El autor utiliza el método ver, juzgar y actuar para indagar y reflexionar sobre la situación actual de la Iglesia, los nuevos paradigmas y las posibilidades del pluralismo. Desde este enfoque urge una educación en los nuevos paradigmas y repensar los fundamentos del cristianismo.

Palabras clave: Pluralismo teológico, Iglesia Católica, Diálogo ecuménico, Método, Nuevos paradigmas, Aparecida, Eclesiocentrismo, Paradigma global, Nueva espiritualidad global.

\section{ABSTRACT}

Along this essay, it is presented the necessity of the theological pluralism as a condition for the dialogue in and outside the Catholic Church. The author uses the method of seeing, judging, and acting to inquire and consider on the current situation of the Church, the new paradigms, and the possibilities of pluralism. From this approach, it is required an education toward the new paradigms and reconsider the bases of the Christianity.

Key words: Theological pluralism. Catholic Church, Ecumenical dialogue. Method. New paradigms. Arisen. Ecclesiocentrism. Global paradigm. New global spirituality.

"A vino nuevo, odres nuevos"

(Mc 2,22)

* Doctor en Educación. Tiene una Maestría en Teología por la Universidad Estatal a Distancia, y una Licenciatura en Filología Hispánica. Ha sido profesor de teología en las Universidades Landivar, Guatemala, y La Salle, Costa Rica. Actualmente se desempeña como Director del Instituto Centroamericano de Ciencias Religiosas (ICCRE), en Guatemala. E-mail: revueltaja@yahoo.es 


\section{Introducción}

"A vino nuevo", es decir, posmodernidad, nuevos paradigmas, otro aire de humanidad conscientemente autónoma y crecida..., "odres nuevos", es decir, nuevo marco teológico, nuevos paradigmas aceptados con semblante optimista. Fiados de Dios.

El 10/09/2010, en la página web Zenit - 'El mundo visto desde Roma', aparecen unas intervenciones de Benedicto XVI sobre el ecumenismo: "Benedicto XVI: Aspectos del gran desafío del ecumenismo"; "Los valores, terreno ecuménico de la colaboración, asegura Benedicto XVI". En esta misma página, en la alocución al episcopado brasileño, en su visita 'ad limina', alude al ecumenismo. Es aprovechable, pero el esquema suena como a "déjà-vu", como a "odres viejos". Algo semejante podríamos aseverar de los Documentos de la Comisión Teológica Internacional ( $C f$. Referencias Bibliográficas).

"Sin diálogo, el ser humano se asfixia y las religiones se anquilosan". Fue en 1993 cuando escribió [R. Panikkar] sentencia tan aforística en un artículo sobre Diálogo inter- e intrarreligioso, recogido luego en Nuevo Diccionario de Teología (2005. Madrid: Trotta, pp. 243 - 251). En él establece las bases del diálogo como alternativa a los fundamentalismos, dogmatismos, anatemas e intolerancias de las religiones y de las culturas hegemónicas, pero también como superación de los monolingüismos, colonialismos y guerras religiosas" (J.J. Tamayo, www.Eclesalia.net, 07/09/'10. A propósito del reciente fallecimiento de Raimon Panikkar).

Bien, totalmente de acuerdo. Pero no vamos a tratar directamente del diálogo intra- y extraeclesial, sino de sus condiciones de posibilidad.

$\mathrm{Su}$ planteamiento lo estructuramos argumentativamente con el método "ver - juzgar - actuar":

VER = Situación eclesial hoy, en relación con el mundo actual, con las religiones y consigo misma.

JUZGAR $=$ Qué nos dice Dios en los Nuevos Paradigmas. Por dónde va creciendo y madurando la $\mathrm{Hu}-$ manidad y su historia.

ACTUAR $=$ Desde el pluralismo: Ir reconociendo que un tema que nació secundario y marginal se está erigiendo, de hecho, en filtro y criterio de la bondad o negatividad de las religiones y sus constituyentes, de la espiritualidad, de la vida humanizada y de la posibilidad del diálogo intra- y extraeclesial.

Lo primero que nota uno al asomarse a este campo es su 
inmensidad, sus posibilidades de futuro, lo pedregoso que resulta, los remolinos y hasta tornados que se forman... y la abundante bibliografía existente en español. Las traducciones no se hacen esperar.

Estas páginas pretenden ser un aporte para la reflexión clarividente y comprometida, sin términos apodípticos y cerrados.

\section{Situación eclesial}

\section{Diálogo imposible}

El diálogo de la Iglesia con la cultura, con la posmodernidad, con las otras iglesias cristianas y con las otras religiones continúa entrampado. No podía ser de otra manera:

Si una de las partes dialogantes se presenta monolítica, encerrada en su caparazón, dispuesta a no ceder en la 'claridad' de sus verdades sagradas, e indispuesta a escuchar, respetar e intentar comprender a la otra parte; así es imposible el diálogo.

De este modo se ha mostrado la Iglesia institucional cristiana a lo largo de los siglos, condenando a diestra y siniestra. Sirviéndose de la Santa Inquisición, de la 'Sodalitium Pianum' (sociedad secreta vaticana, fundada en 1907, bajo el pontificado de San Pío X, con la finalidad de detectar, delatar y condenar a los modernistas en la Iglesia), del Santo Oficio -hoy llamado
'Congregación para la Doctrina de la Fe' (CDF). Esta especie de "caza de brujas" ha continuado después del Concilio Vaticano II, hasta nuestros días, en pleno siglo XXI.

Las llamadas de atención, condenas y destituciones, se han sucedido en los tres últimos decenios. Todos guardamos in mente a más de una veintena de prominentes teólogos señalados por la CDF: Desde I. Congar (+), H. de Lubac $(+)$, Th. de Chardin (+), H. Küng y E. Schillebeeckx (+); hasta J.M. Castillo, J.A. Estrada, Ivone Gebara, Anthony de Mello (+), J. Sobrino, L. Boff o Marciano Vidal. Más cercanos, J. Dupuis (+), J.J. Tamayo-Acosta, R. Haight, J.M. Vigil.

Sobre este último -es un ejemplo- se manifiesta la Asociación Ecuménica de Teólogos/as del Tercer Mundo (ASETT), en carta de enero del 2008 (Alternativas, 2008: 249ss):

No podemos dejar de expresar nuestra tristeza al saber que la Comisión para la Doctrina de la Fe de la Conferencia Episcopal Española ha divulgado una nota de censura y condenación contra el libro Teología del pluralismo religioso, de la autoría de José María Vigil... Lamentamos que pastores cristianos que debieran dar al mundo un ejemplo de ser personas de diálogo, condenen un libro sin conversar con el autor, y sin escuchar al menos una opinión divergente de las suyas. 
No se dan cuenta de que la preocupación de reflexionar sobre la fe a partir de presupuestos culturales nuevos, al contrario de lo que prejuzgan, renueva la posibilidad espiritual para una multitud inmensa de seres humanos que no consigue ya acoger el mensaje del reino de Dios si viene de una Iglesia autoritaria y cerrada en su dogmatismo.

Como entidad ecuménica y responsable de incentivar la investigación teológica, la ASETT está convencida de que, más peligroso para la fe que cualquier error doctrinal que por acaso estuviere contenido en las entrelineas de un libro como el de Vigil, sería el fin de la elaboración teológica, al ser reprimida por el cercenamiento de la libertad de pensamiento y por el rechazo eclesiástico de un sano pluralismo de investigación en las Iglesias cristianas.

\section{Eclesiología de cristiandad medieval}

Hasta hoy, los Papas han profesado una mentalidad de Iglesia de Cristiandad, de ideal más o menos medieval. Acaso el más ilusionado con este modelo haya sido el popular Juan Pablo II, a pesar de sus grandes gestos. Ejemplo, los Encuentros de Oración Interreligiosa de Asís.

En el aspecto teológico-dogmático no se podían hacer innovaciones, nuevos planteamientos o cuestionar algún tema. Todo continuaba congelado, en contra del dinamismo evolucionador de la naturaleza y de la historia. Y con oposición cerrada a todo lo que supusiera progreso.

Por ello, a medida que pasaban los años del posconcilio, se reforzó el control de Roma y las advertencias sobre la enseñanza de la teología, a la que el Concilio había dado libertad de investigación (GS 62, 7).

Se fijó la doctrina oficial en el "Catecismo de la Iglesia Católica" $\mathrm{y}$, lo que es más grave, la organización eclesiástica quedó intacta. El resultado fue que la Iglesia funciona igual que antes del Concilio, más preocupada por mantener el propio prestigio y posición en la sociedad que por la evangelización propiamente dicha.

Actúa a la defensiva, frenando la innovación e intentando reconstruir un sistema rígido que se está desmoronando. Incluso en el Documento de Aparecida (n. 43ss) se muestra esta actitud pesimista.

"Tenemos que ser conscientes de que las corrientes culturales -en nuestro caso la modernidad y posmodernidad-son irreversibles y de nada sirve ignorarlas $u$ oponerse a ellas. Las consecuencias de esta actitud son el empobrecimiento intelectual y la falta de capacidad para entender las transformaciones de la sociedad" (García-Zamorano, 2010: 47). 


\section{La declaración "Dominus lesus"}

Pero el shock teológico más impactante y negativo en el mundo académico católico y protestante fue la publicación de la Declaración "Dominus Iesus" (6 de agosto de 2000). Su finalidad, "confirmar de nuevo la fe de la Iglesia" (n. 23). Ya el subtítulo indica la tesis que proclama: "Sobre la unicidad y la universalidad salvífica de Jesucristo y de la Iglesia".

Con este enunciado podemos sospechar el eclesiocentrismo y el cristocentrismo de que está traspasada toda la Declaración. Un resumen acabado de las verdades que defiende lo encontramos en la primera parte del n. 4 :

El perenne anuncio misionero de la Iglesia es puesto hoy en peligro por teorías de tipo relativista, que tratan de justificar el pluralismo religioso, no sólo de facto sino también de iure (o de principio). En consecuencia, se retienen superadas, por ejemplo, verdades tales como el carácter definitivo y completo de la revelación en Jesucristo, la naturaleza de la fe cristiana con respecto a la creencia de las otras religiones, el carácter inspirado de los libros de la Sagrada Escritura, la unidad personal entre el Verbo eterno y Jesús de Nazaret, la unidad entre la economía del Verbo encarnado y del Espíritu Santo, la unicidad y la universalidad salvífica del misterio de Jesucristo, la mediación salvífica universal de la Iglesia, la inseparabilidad-aun en la distinción-entre el Reino de Dios, el Reino de Cristo y la Iglesia, la subsistencia en la Iglesia católica de la única Iglesia de Cristo.

Diríase que la Declaración "Dominus Iesus" es heredera -al comienzo del siglo XXI- de estos textos de los Papas "Pío":

"80.- El romano pontífice puede y debe reconciliarse y transigir con el progreso, con el liberalismo y con la civilización moderna". (Última proposición del 'Syllabus', condenada por Pío IX en 1864. -Denzinger, 1963: 413).

"Esta iglesia es por esencia una sociedad desigual, es decir, una sociedad que comprende dos categorías de personas, los pastores y el rebaño...Estas categorías son tan distintas entre sí que sólo en el cuerpo pastoral residen el derecho y la autoridad necesaria para promover $y$ dirigir a todos los miembros hacia el fin de la sociedad; la multitud no tiene más deber que el de dejarse conducir y seguir como dócil rebano a sus pastores" (De la encíclica 'Vehementer nos' al clero y pueblo de Francia, 11 febrero 1906, de San Pío X).

“... se apoyan en la opinión errónea de que todas las religiones son más o menos buenas y loables... Los que mantienen esta opinión rechazan 
por eso la religión verdadera" (De la encíclica 'Mortalium animos', del 6 enero 1928, de Pío XI).

El 12 de agosto de 1950, Pío XII publica la encíclica 'Humani generis' "sobre ciertas opiniones falsas que amenazan con arruinar los fundamentos de la doctrina católica". Condena la llamada "nueva teología" y pide que se vuelva a la ortodoxia tomista en los terrenos filosófico y teológico (Denzinger, 1963: 599ss).

Después de los paréntesis de Juan XXIII, Concilio Vaticano II y primeros años del papado de Pablo VI -verdaderos oasis de la teología católica- continuamos hoy con paradigmas semejantes a los de la época piana.

Con tales planteamientos fijos bajo el brazo es deshonesto sentarse en una mesa de diálogo ecuménico o de diálogo interreligioso. Es deshonesto presentarse así ante una sociedad moderna y posmoderna. Es deshonesto dirigirse en esos términos a un hombre moderno que se va abriendo a una nueva conciencia, a una nueva comprensión de relacionalidad con el mundo y con la historia.

Tal vez una posible salida honesta y científica -desde el mismo cristianismo- sea el pluralismo religioso/teológico.

También la "Dominus Iesus" comenta el modo por el cual la gracia salvífica es donada a los no cristianos: "El Concilio Vaticano II se limitó a afirmar que Dios la dona 'por caminos que Él sabe' (Decreto 'Ad gentes', 7). La Teología está tratando de profundizar este argumento, ya que es sin duda útil para el crecimiento de la comprensión de los designios salvíficos de Dios y de los caminos de su realización" (DI, 21). Efectivamente una pléyade de teólogos prosigue indagando científicamente, conforme con la nueva sensibilidad cultural humana, los caminos de ese 'argumento'. Esos caminos son los Nuevos Paradigmas.

\section{Nuevos paradigmas}

La situación eclesial actual, desfasada de las corrientes de la vida, podría ir empistándose si analizara en libertad y si viviera los nuevos paradigmas que se están afianzando en este nuestro momento histórico de cambios radicales. Constituye su obligación moral más grave, si quiere ser fiel a su identidad.

Apuntamos dos notas sobre "paradigma", término de moda y casi de empleo abusivo.

Paradigma: Del latín 'paradigma', $\mathrm{y}$ éste del griego 'parádeigma' = modelo, ejemplo < 'paradéiknimi' $=$ mostrar, manifestar. 
En uso general: "ejemplo", "ejemplar", "modelo", "referencia".

Ya aparece en la 'Retórica' de Aristóteles, utilizado con el valor de "ejemplo". Y en la dialéctica platónica, como "modelo" eterno de la cosa sensible, según su doctrina de las ideas y su conocido mito de la caverna.

"Paradigma" designa un marco de pensamiento, una estructura mental que permite comprender y explicar ciertos aspectos de la realidad.

Cuando surgen nuevos problemas, insolubles con la ayuda de los principios metodológicos antiguos, se forma un nuevo paradigma -más amplio y englobante que el anterior- como solución explicativa posible.

El resonante éxito del término paradigma se ha de atribuir a la filosofía postempirista de la ciencia, inspirada en la subversión de la física newtoniana, e iniciada por Bohr, Planck y Einstein con su física cuántica y teoría de la relatividad.

Trajo a la superficie las grandes preguntas sobre la realidad y viabilidad de la revolución científica. Fue introducido en Epistemología a partir de los años 60 y contribuyó a la renovación de la teoría de la ciencia. Es el 'impasse' de cambio en que estamos inmersos ahora.

La historia de la ciencia oscila, según esa interpretación de Kuhn, al ritmo de revoluciones y normalizaciones. $\mathrm{Y}$ esto de forma no lineal y no acumulativa, ya que todo paradigma victorioso conlleva una visión distinta de la naturaleza, que sirve de marco -inconsciente y difuso- en la consecución de los nuevos estudios y observaciones.

Por ser 'visiones del mundo' incorporan valores y procedimientos de investigación nuevos. Para Kuhn, los paradigmas son inconmensurables, por lo cual no se puede hablar de ciencia en singular, sino de "tipos" o "campos" de ciencia. También son incompatibles: o uno u otro, como en los casos de la mecánica newtoniana y de la física cuántica; geocentrismo o heliocentrismo; Iglesia de cristiandad o Plan de Dios (Reino). Ocurre que un término o expresión o símbolo idénticos no significan lo mismo en un Paradigma que en otro. Por eso no se puede juzgar un Paradigma desde otro. Ejemplo clásico es el de los cardenales que juzgan a Galileo y su heliocentrismo, con el pasaje bíblico geocéntrico de Josué.

Muchos autores ven a los nuevos paradigmas tan interconectados, tan semejantes y con rasgos tan comunes, que los agrupan en el Nuevo Paradigma Global. Su consideración "Global" es entendida en tanto que incluyente de los nuevos paradigmas parciales de las diferentes parcelas científicas.

Estamos viviendo el paso del Viejo al Nuevo Paradigma. Esto 
se nota en la Nueva Espiritualidad Global, en el mundo religioso de los creyentes y en la nueva teología.

Vamos a señalar algunos de los nuevos paradigmas más decisivos en la decantación y justificación del PLURALISMO religioso-teológico. Él está haciendo cambiar de raíz la perspectiva y el enfoque de la teología cristiana...y las relaciones intraeclesiales y extraeclesiales.

\section{Nuevo paradigma global contemporáneo, producido por una explosión del conocimiento}

Se puede hablar de paradigmas científicos, paradigmas teóricos, paradigmas prácticos...y se puede hablar también de paradigmas como cosmovisión, "Weltanschauung", concepciones globales sobre el mundo y sobre la realidad misma en su totalidad.

Frijof Capra es uno de los autores que mejor y más comprehensivamente ha relacionado sociedad, política, cultura, ciencias, ética y espiritualidad. En El punto crucial analiza y argumenta con lucidez y claridad meridiana que estamos en una encrucijada, en un dramático cambio de conceptos e ideas en nuestra visión del mundo, desde el campo de la física. Pasamos de una concepción mecanicista, cartesiana-newtoniana, a una visión organicista, holística y ecológica.
La teoría de sistemas (o integral) sobre la vida, la mente, la conciencia y la evolución; el enfoque holístico de la salud y de la enfermedad; la integración de los enfoques orientales y occidentales de la psicología y psicoterapia; la perspectiva ecológica y feminista (espiritual por naturaleza); etc... están dando origen a cambios profundos en nuestras estructuras sociales, políticas y religiosas -asegura Capra en sus obras.

Se trata de algo alternativo, NUEVO, distinto a lo anterior. Va apareciendo poco a poco. Y supone un nuevo pensar, una nueva totalidad (opuesta al mecanicismo materialista del antiguo paradigma), una nueva conciencia (del yo egocentrado y mental hacia el yo psíquico abierto y transpersonal), una nueva visión del mundo (monista y holística); una novedad radical.

Tenemos que reconocer que hemos crecido y nos hemos formado en el paradigma científico reduccionista antiguo. Pero estamos en el inicio del punto de inflexión, del 'quiebre', de la bifurcación de nuestra civilización. "Vivimos un cambio de época" (Aparecida, 44).

Alegrémonos porque vivimos un momento de 'macrometanoia' (Nemeth, 1994: passim) histórica: Una verdadera oportunidad.

Por supuesto, también en el plano religioso. Muchos artículos y libros lo constatan y estudian 
científicamente. Un ejemplo, Juan Martín Velasco, en El malestar religioso de nuestra cultura.

En el siglo XVI se produjo la Revolución Copernicana: El Heliocentrismo. A fines del siglo XX comienza a producirse la Revolución de las Ciencias: El Cosmocentrismo. Con las nuevas cosmovisiones generadas por ellas.

Hoy las ciencias de frontera roturan campos nuevos en extensión y en profundidad. Obedecen a los principios del Nuevo Paradigma Global y se están creando constantemente. Multiplican las redes, las conexiones y convergencias que permiten llegar a un saber unificado y unificante que integra todas las dimensiones de la realidad. Ejemplos: Física Cuántica, Astrofísica, Neurobiología, Nanomedicina, Cibernética, Teoría de Sistemas, Teoría del Caos, Teoría de la Complejidad, Nanotecnología, Arquitectura Biónica, etc.

Nuevo Paradigma Global producido por la ampliación explosiva del conocimiento:

- En cantidad: Disminuye apresuradamente el número de años en que se duplica la información.

Los conocimientos han crecido y se han multiplicado exponencialmente, pero ese crecimiento cuantitativo es nada en comparación con la importancia del cambio cualitativo, del cambio de horizonte que ese mismo crecimiento exponencial ha producido. El cambio cuantitativo de conocimientos, con ser muy grande, queda pequeño en comparación con la significación del cambio del marco epistemológico y hermenéutico en el que se insertan aquellos conocimientos nuevos.

- En calidad: La sociedad se ha hecho reflexiva...

- En el acceso a lo micro: Molecular, nanotecnológico, atómico, subatómico, cuántico...

- En el acceso a lo macro: Planetario, satelital, telescopios, astronomía...

- En el acceso al pasado: Paleontología, geología, origen y evolución del universo, 'big bang' ...

- En el acceso a la intimidad de la vida: Genes, ADN, ingeniería genética...

- Con la ayuda de la informática...

\section{Nueva espiritualidad global}

Desde los pasados años 60 y 70 vienen aumentando notoriamente los caminos, manifestaciones y metas positivas de experiencia espiritual humana, hasta poderse hablar de una Nueva Espiritualidad de la vocación humana en la historia... 
no vivida en términos religiosos, sino sólo "humanos" (en principio).

Era natural que al cambiar de Paradigma Global cambiaran las formas de pensar, las actitudes y los valores, hasta construir una Espiritualidad nueva.

La Espiritualidad, lo espiritual, es un rasgo antropológico común a todos los humanos. Esta Espiritualidad (E) se manifiesta en DOS PLANOS:

1. Espiritualidad humana fundamental, natural, vital, ético-política.

2. Espiritualidad humano-religiosa, creyente en el misterio trascendente, en el Todo, en Dios.

Espiritualidad humana-fundamental: Todas las personas, por el hecho de ser humanas, poseen esta Espiritualidad. Es "no religiosa" en el sentido convencional usual del término; sin querer negar el carácter antropológicamente religioso de toda "profundidad" personal. Esta E. bebe en las fuentes de la vida, la historia, la realidad social, la praxis, la reflexión, la sabiduría, la contemplación, es decir, todas aquellas fuentes de la razón y del corazón. Puede ser positiva, si humaniza; negativa, si deshumaniza.

La espiritualidad humano-religiosa puede ser genérica o específica.
"En ambos modos está presente y actúa el Espiritu de Dios. Ambos modos de E. están inmersos en el régimen de la Salvación... La diferencia específica se sitúa en el orden del conocimiento de la Salvación, no en el de la realización de la mis$m a$ " (Casaldáliga- Vigil, 1993: pp. $38-39)$.

Se trata de dos modos diferentes, pero no excluyentes ni alternativos. Efectivamente, la 1. es condición de la 2.

La separación entre lo material y lo espiritual, lo profano y lo sagrado, se concreta en otra distinción muy frecuente: Se piensa que la vida espiritual es sólo para el 'alma', mientras que el cuerpo y los goces corporales son un obstáculo para la E. Por eso algunos llegan incluso a despreciar el cuerpo y a reprimir sus necesidades más legítimas (dualismo acientífico).

A su vez se superó la mentalidad estrecha que hacía de la E. un monopolio de las personas religiosas... Si 'Espiritualidad' es el "horizonte significativo de la existencia humana", debe atribuirse a todo hombre o mujer que estén abiertos al misterio, a la realidad, a la trascendencia, y que vivan según sus verdaderas dimensiones humanas.

La persona es una dimensión de la Tierra y del universo. Interiorizar esta realidad de pertenencia, experimentarla y sentirse insertado y cargado por la dinámica del 
universo y por el Espíritu que la impregna es ser espiritual y elaborar espiritualidad (Boff, 2003: p. 58s).

Nueva Espiritualidad es "el modo de consciencia en el que el individuo experimenta un sentimiento de pertenencia y de conexión con el cosmos como un todo" (Capra, 20036: p. 29).

Coincide con las tradiciones espirituales de todos los tiempos: Orientales, la de los místicos cristianos, la de los sufíes musulmanes, la de los nativos americanos, etc.

Cuando la persona hace la experiencia interior de este sentimiento de pertenencia y de conexión con el TODO, trascendiéndose, vive la Nueva Espiritualidad Global.

Espiritualidad nueva es la búsqueda de orden, de una transformación dentro de nuestra conciencia, lo cual se manifiesta en distintas formas, como amor, compasión o libertad.

\section{Nueva situación epistemológica}

"La mayor aportación del conocimiento del siglo XX ha sido el conocimiento de los límites del conocimiento" (Morin, 2003: 71). Y en religión y en teología, esta aportación ha sido decisiva.

Nuestra generación está experimentando y realizando el cambio. Heredamos un conocimiento teológico y religioso ingenuamente realista, en el que todas las afirmaciones tenían una significación directa, literal, unívoca, y estamos viviendo ya hoy una epistemología radicalmente diferente.

Podemos destacar principalmente estos cambios:

- Se acabó la «epistemología mítica», que interpretaba literalmente las creencias religiosas y las afirmaciones teológicas, sencillamente como si estuviese describiendo directamente la realidad a la que apuntan. Todas nuestras afirmaciones religiosas, míticas o mitológicas, pero también aquellas otras más sobriamente «metafísicas», ontológicas, sobrenaturales o teológicas... eran tenidas por descripción exacta de una realidad religiosa a la que correspondían.

- Se acabó el «realismo ingenuo» del conocimiento, por el que creíamos que se daba una correspondencia directa y lineal entre nuestro lenguaje y la realidad a la que nos referíamos, realidad perfectamente describible con nuestro lenguaje. Hoy nos hemos hecho conscientes de que entre nuestras afirmaciones y la realidad, media un hiato desconocido, del que apenas estamos entrando a conocer sus dimensiones y su significación. Hoy hemos 
descubierto que nuestro conocimiento religioso no nos traslada al mundo de la realidad religiosa, sino sólo a «un mapa» del mismo.

- Estamos descubriendo que hemos pasado la historia mirando por unos lentes, de los que sólo hoy nos hemos hecho conscientes. La realidad no es la que veíamos, ni era como la veíamos. Hoy nos llenamos de comprensión hacia nosotros mismos, hacia los demás, hacia nuestras interpretaciones anteriores del mundo y, concretamente, hacia nuestras interpretaciones religiosas del mundo y hacia nuestras peleas filosóficas y religiosas, pues comprendemos los «espejismos», las ilusiones ópticas de que hemos sido víctimas, efectos ópticos mezclados tantas veces con nuestros intereses $y$ nuestras limitaciones, de unos y de otros. Hoy nos hacen sonreír, como «juegos de niños» que en realidad venían a ser. Humildemente admitimos que tenemos que corregir nuestras percepciones y nuestras convicciones epistemológicas clásicas.

- Hoy sabemos que «todo conocimiento es interpretación», y que es producido parcialmente también por el sujeto cognoscente pues interviene en el conocimiento, en el sentido de que pone la pregunta, la cual condiciona el modo y el sentido en el que será captada. Así toda experiencia religiosa está mediada: No existe la experiencia religiosa pura, sin interpretación, sin mediación de lenguaje, de categorías de pensamiento y de cultura que la fragüen desde el primer momento. No hay un mundo objetivo de verdades, al cual nuestro intelecto pudiera "adecuarse" (según la adaequatio rei et intellectus de la definición aristotélica). Se cumple el Principio de Indeterminación de Heisenberg, según el cual las partículas atómicas no siguen la línea causa-efecto, sino que se organizan dentro del Principio de indeterminación de las probabilidades. Al ser probabilidades, abiertas a concretarse o no, es imposible describirlas. Fue Heisenberg quien experimentó la imposibilidad de medir simultáneamente la velocidad y la posición de una partícula: Cuando mide la velocidad, la posición de la partícula ya cambió, y al revés. De modo que hay una radical indeterminación en el mundo subatómico.

Parecido a nosotros: El sujeto que observa influye en el fenómeno observado. El sujeto forma parte 
de la constitución de lo real. "Describiendo lo real, estamos autodescribiéndonos" (Boff, 2000: 47 y 48). Somos quienes definimos el campo real que observamos. "La realidad sucede cuando la vemos" (D. Zohar, citada por Boff, 2003: 55).

"La mayor aportación del conocimiento del siglo $X X$ ha sido el conocimiento de los límites del conocimiento. La mayor certidumbre que nos ha dado es la de la imposibilidad de eliminar ciertas incertidumbres, no sólo en la acción sino también en el conocimiento". (Morin, 2003: 71-72).

Estamos llenos de incertidumbre, pero más seguros de estar más cerca de la verdad. Todo está relacionado con todo.

También podríamos adjetivar a las formulaciones religiosas como holísticas, sistémicas, interconectivas, sinérgicas, en red...

\section{Nueva concepción de "revelación"}

Primeramente hay que tomar de la manera más seria posible el principio de que a Dios nadie lo ha visto (Jn 1, 18; 1Tim 6, 16)

El viejo concepto -el que nos enseñaron a todos-arrastra la idea de que, si bien [la Biblia] no es un libro literalmente 'caído del cielo', sí es algo equivalente: un libro que ha sido inspirado por Dios a los seres humanos que lo escribieron. Éstos eran instrumentos en manos de Dios: causa instrumental, con diversidad de explicaciones, según los manuales clásicos del Tratado de Revelación.

Durante milenio y medio se tuvo la concepción de que la revelación bíblica es sobre todo "palabra", con todo lo que ello lleva aparejado de verbalismo y conceptualismo; una revelación entendida primordialmente como doctrina, verdades reveladas, 'depósito' de verdades que hay que conservar y preservar intactas. Así se lo hemos repetido machaconamente al pueblo fiel.

Hoy se admite con normalidad el enfoque de que la revelación se da en un proceso humano y dentro de la historia. Por ejemplo, la aceptación de los «géneros literarios» en la Biblia supuso toda una revolución epistemológica para nosotros, pues permitía descargar de significación literal descriptiva a muchos contenidos del acervo de nuestro conocimiento religioso y teológico que hasta entonces habían sido intocables e ininterpretables.

La revelación no es -en realidad- unas palabras o unos textos, sino el proceso vital existencial de un pueblo que hizo una experiencia religiosa, experiencia que se materializó finalmente en una expresión escrita. La revelación no es el texto, no son las palabras, no es el libro. 
Es más bien el proceso, la experiencia religiosa misma por la que ese pueblo trató de darse un sentido para su vida, a partir de los mitos del mundo religioso y cultural en que vivía. Es "la revelación divina en la realización humana" (Torres Queiruga, 2008: Subtítulo).

En definitiva, la palabra de Dios es la palabra de los hombres que hablan de Dios. Es sólo indirectamente la palabra de Dios. La persona humana sólo puede hablar de Dios en tanto que habla de sí misma, en tanto que habla de una manera antropomórfica y antropopática: No podemos expresarnos acerca del misterio o de la trascendencia más que poéticamente, con analogías, metáforas, símbolos, leyendas, dramatizaciones, relatos mitológicos, etc.

Lo que hoy llamamos fundamentalismo, o simplemente mentalidad conservadora, ha sido la postura dominante en el cristianismo durante milenio y medio. El protestantismo fue el primero en abrirse a un modo de pensamiento "moderno", crítico, en un proceso laborioso y hasta doloroso, que comenzó en el siglo XVIII. El catolicismo permanecerá cerrado a la renovación teológica y bíblica del mundo protestante, al menos hasta los años 40 del siglo XX (La encíclica Divino Afflante Spiritu, de Pío XII, en 1943, significó la apertura, la admisión dentro del catolicismo de los métodos científicos o críticos de acceso a la Escritura. La consolidación de esta apertura no se daría hasta el Vaticano II, en 1965). Y por miedo o escrúpulo, por desconfianza hacia los creyentes católicos o por falta de fe, no se les ha comunicado con sencillez el estado de la cuestión.

Se ha practicado la norma tácita de una "doble verdad": por un lado, la de los eruditos y universitarios y, por otro, la que se transmite a los fieles creyentes. Se mantiene al pueblo en un infantilismo desconfiado e hiriente, mientras que la "otra verdad" es para los especialistas, teólogos, exegetas y gente informada. Esta situación produce esquizofrenia en los fieles.

No hay "revelación" en sentido clásico. El testimonio de un anciano Schillebeeckx (recientemente fallecido) es esclarecedor:

La palabra de Dios es la palabra de los hombres que hablan de Dios. Decir "sic et simpliciter" que la Biblia es la palabra de Dios no se corresponde con la verdad. Es sólo indirectamente la palabra de Dios... Cuando la Biblia dice: "Dios ha dicho, Cristo ha dicho..." no es Dios quien lo ha dicho, no es Cristo quien lo ha dicho en sentido estricto, sino los hombres que han contado su experiencia de relación con Dios... No se da nunca un encuentro directo, de tú a tú, de Dios con el hombre, sino siempre a través de mediaciones. 
No se puede comprender la nueva teología sin este concepto de revelación mediada por la historia, por la experiencia interpretativa de los hombres. Cuando no se acepta la mediación, se cae necesariamente en el fundamentalismo (Schillebeeckx, 1994: 72-73).

Este es el nuevo paradigma hermenéutico. La gran revelación de Dios es la naturaleza. Los libros religiosos son obra de hombres, no revelación directa de Dios. La historia del cosmos es nuestra Historia Sagrada, nuestro gran relato.

"Actualmente se está produciendo un fenómeno impresionante. Me refiero a la transformación radical de la imagen del mundo que va produciendo el relato cósmico de nuestro origen y desarrollo en la medida en que va penetrando en la conciencia humana" (Swimme, 1998: 10). ¡Un nuevo y profundo momento revelatorio!

\section{Nuevo pluralismo}

"Muchas veces los lenguajes utilizados parecieran no tener en cuenta la mutación de los códigos existencialmente relevantes en las sociedades influenciadas por la postmodernidad y marcadas por un amplio pluralismo social y cultural" (Documento de Aparecida, 100d).

Añadiríamos que no sólo "los lenguajes", sino las cosmovisiones, el Nuevo Paradigma Global, la Nueva
Espiritualidad Global, la nueva situación epistemológica y la Nueva Teología del Pluralismo Religioso.

'Aparecida' reconoce el pluralismo social y cultural. Pero ¿qué entendemos por "pluralismo"?:

- El reconocimiento de muchos sistemas, principios o realidades. En política, tendencia a permitir y reconocer la expresión y difusión de diversas opiniones, incluso las opositoras a las gubernamentales, en la dinámica de las sociedades democráticas. En teología, el pluralismo es la posición que defiende que todas las religiones son caminos para llegar a Dios y a la salvación. La diversidad de culturas y de religiones es hoy un hecho; es un espacio de manifestación divina, por tanto, querido por Dios; Dios quiere que todos los hombres se salven.

- Teología del Pluralismo Religioso sería repensar lo cristiano desde la nueva perspectiva pluralista.

- Del evidente pluralismo (o pluralidad) social y cultural pasamos al pluralismo religioso, como perteneciente a la misma realidad. 'Pluralidad' es una variable externa; 'pluralismo' es una actitud interna de tolerancia primero, y de aceptación después. 


\section{Pluralismo religioso desde el cristianismo}

¿Hay salvación fuera de nuestra religión?

¿Es necesario convertir al cristianismo a las personas de otras religiones, para agradar a Dios?

¿Dios quería una sola religión?

¿Cómo, después de 2000 años, todavía dos terceras partes del mundo no son cristianos? ¿Qué es lo que ha fallado: Dios, las iglesias, los misioneros, los que llamábamos 'infieles'?

¿Qué se podrá hacer para acelerar la "conversión del mundo" a la religión cristiana? (Porque hoy no parece posible) ¿O basta que se convierta a Jesucristo? ¿O no hace falta siquiera eso?

La fe cristiana ies verdadera? ¿es verdad? ¿es la verdad? ¿es 'verdad para algunos'? ¿es 'la verdad para todos'? ¿es una verdad entre muchas?...Podríamos seguir con más interrogantes.

El pluralismo religioso, más que un tema teórico, es una realidad que nos rodea. Nos topamos con ella aun sin pretenderlo. Y sus cuestionamientos provienen de la sociedad de hoy.

Desde los albores de la humanidad, las sociedades humanas siempre han vivido en su pequeño mundo, en su hábitat, como encerradas en sí mismas y aisladas de las demás, sin conocer otra cosa que su propia existencia.

Hoy, por el avance y mejora de los medios de comunicación (transporte, viajes, telecomunicación, NTICs...) las sociedades se han ido incorporando a una interacción y un conocimiento mutuos, de modo que, en los últimos decenios, el fenómeno sociológico mayor es la mundialización. 'Mundialización' en el sentido de que el mundo se está haciendo uno, de que todas las dimensiones de la sociedad se están interrelacionando y volviéndose mutuamente dependientes.

Las culturas y las religiones de cada sociedad, que hasta ahora vivieron aisladas y mutuamente ignorantes, se hacen vecinas y se ven obligadas a convivir. Somos la primera generación de toda la historia de la humanidad que se encuentra en esta situación. Nueva, por tanto; al menos con estas dimensiones mundiales.

\section{Teología del pluralismo religioso}

"Una teología de la biodiversidad, no sólo testimonia que la diversidad de las culturas y religiones es un espacio de manifestación divina, sino que, en esta relación amorosa de Dios con la humanidad cada vez más plural, la divinidad se viste de formas diversas y asume como atributo divino, no sólo la unidad, sino la diversidad" (Barros, 2007: 66). 
En pleno Vaticano II (1963), Robert Schlette publica su obra "Teología de las Religiones" -primer libro de esta materia. El tema central de discusión de esta joven teología versaba sobre si hay salvación en las otras religiones. Hoy nos parece obvio que hay salvación fuera del cristianismo. Pero hasta el Vaticano II no fue así.

La 'teología de las religiones' evolucionó hasta fijarse en una nueva temática y sus consecuencias para el cristianismo: El pluralismo religioso, el pluralismo de las religiones, el hecho de que sean muchas y no una. Entonces pasó a llamarse "Teología del Pluralismo Religioso".

\section{Tres categorías de análisis}

Las consideraciones de su estudio han dado en una clasificación tripartita, universalmente admitida: A) Exclusivismo B) Inclusivismo C) Pluralismo. (Para otras tipologías o clasificaciones más detalladas, cf. Vigil, 2005: 55-56).

En el ámbito cristiano, se utilizan otras categorías paralelas, también generales y claras, pero ya explícitamente teológicas:

A) Eclesiocentrismo: De hecho, en el cristianismo, la posición exclusivista no puede sino poner en el centro de todo a la Iglesia cristiana. Sólo la Iglesia es depositaria de la salvación; todas las demás religiones están destinadas a desaparecer. Todo en el mundo y en la historia humana apunta a la Iglesia como a su centro y destino.

B) Cristocentrismo: Sería el nombre cristiano del inclusivismo. En las religiones no cristianas también hay Verdad de Dios y Salvación. Pero éstas son las propias del cristianismo, las que manifestó Jesucristo, Hijo de Dios venido a este mundo. Nadie se salva si no es por la mediación de Cristo, aunque no lo conozca.

C) Teocentrismo: Esta tercera posición sostiene que quien está en el centro es Dios y sólo Dios. En su derredor están todas las religiones, que se relacionan con Dios directamente, sin la mediación cristiana.

Vamos a tratar brevemente estas tres posturas de la Iglesia católica en sus XX siglos de existencia. Son la clave para entender el diálogo eclesial.

Exclusivismo / Eclesiocentrismo: "Fuera de la Iglesia no hay salvación"

Se llama exclusivismo a la posición teológica que sostiene que hay una única religión verdadera, que es la que ha sido revelada por Dios, y que tiene en exclusiva la verdad, mientras que las otras son 
religiones falsas, o religiones simplemente humanas, o naturales, que no salvan.

Hasta la segunda mitad del siglo XX, la posición hegemónica $\mathrm{y}$ oficial en el cristianismo ha sido la del exclusivismo. Si bien en tan larga historia se contemplan algunas excepciones, por ejemplo: Raimundo Lulio (1232 - 1316), Nicolás de Cusa (1401 - 1464) o Erasmo de Rotterdam (1467 - 1536).

La expresión simbólica que resume el exclusivismo es la famosa sentencia "extra Ecclesiam, nulla salus" (fuera de la Iglesia no hay salvación). Atribuida a Orígenes, a San Cipriano o a Fulgencio (siglo VI), el caso es que fue asumida por el concilio de Florencia en 1442 en su decreto contra los Jacobitas. Rotunda y oficialmente afirma que "firmemente cree, profesa y enseña que ninguno de aquellos que se encuentran fuera de la Iglesia católica, no sólo los paganos, sino también los judíos, los herejes y los cismáticos podrán participar de la vida eterna. Irán al fuego eterno que ha sido preparado para el diablo y sus ángeles (Mt 25, 41)... (Denzinger, 714).

Esta doctrina se mantuvo expresa y autoritativamente hasta el Vaticano II. En la segunda mitad del siglo XIX declaraba el Papa Pío IX (1846 - 1878): “...esa impía y nociva idea: que el camino de la salvación eterna puede encontrarse en cualquier religión. Ciertamente debemos mantener que es parte de la fe que nadie puede salvarse fuera de la Iglesia apostólico-romana, que es la única arca de salvación y que quien no entra en ella va a perecer en el diluvio. Pero sin embargo debemos de la misma manera defender como cierto que aquellos que se afanan en la ignorancia de la fe verdadera, si esa ignorancia es invencible, nunca serán acusados de ninguna culpa por esto ante los ojos del Señor" (Pío IX, Singulari Quadam, Acta Pii IX, III, p. 626).

Acá ya abre la puerta de la salvación a los de 'ignorancia invencible'. Por eso la urgencia de la acción misionera, para hacer posible que puedan incorporarse a la Iglesia, única posibilidad de salvación. En el campo católico, exclusivismo es equivalente a eclesiocentrismo como dijimos ya.

Así que durante casi veinte siglos la Iglesia ha defendido, consciente y solemnemente, esta solemne "monstruosidad". ( La palabra es de Torres Queiruga, 1992: 4 y 7. Otros han empleado sinónimos de ese término).

Inclusivismo / Cristocentrismo: "Sólo Cristo salva"

Sostiene que la salvación para la humanidad habría sido conquistada únicamente por Jesucristo, quien la ha depositado en su Iglesia. 
Participan también de la salvación los no cristianos, pero no por una supuesta validez de sus propias religiones, sino por el poder de Cristo, que les alcanza "de una manera sólo de Dios conocida" (Gaudium et Spes, 22).

La misma Iglesia católica fue la que dio el paso del exclusivismo al inclusivismo, en torno al tiempo del Vaticano II. Dos posiciones prepararon el camino:

a. La teoría del "cumplimiento": Se llama así porque defiende que para las religiones, el cristianismo viene a ser el "cumplimiento", es decir, su consumación y, en este sentido, su acabamiento, su plenitud y, también, su superación.

Las religiones no cristianas no tienen capacidad salvífica por sí mismas, pues son religiones "naturales", obra del ser humano, que busca a Dios (pensamiento semejante al de Karl Barth). Sin embargo, la salvación de Cristo llega a las personas que están en esas religiones porque Dios responde a las aspiraciones de los hombres y mujeres que le buscan con las mediaciones de que disponen.

En esta corriente están, con diferentes matices, Jean Danielou, Henri de Lubac y Urs von Balthasar. Y algunos de nuestros contemporáneos. b. La teoría de "los cristianos anónimos": Elaborada por K. Rahner (1904 - 1984), fue la que más influyó en el concilio Vaticano II. Supuso un avance. Era la primera vez que en el cristianismo se decía de un modo tan explícito y fundamentado que la gracia y el misterio de Cristo desbordaban la Iglesia. Era una visión llena de optimismo, frente al pesimismo de la visión exclusivista. El de Rahner es un inclusivismo cristocéntrico: toda la humanidad queda incluida en la salvación de Cristo. No hay dos historias, sino que la acción salvadora de Dios en la historia la abarca toda.

Tanto los miembros de otras religiones, como los ateos, si hacen de alguna manera una experiencia originaria de Dios, entran -para Rahner- en la categoría de "cristianos anónimos".

En este contexto fue muy comentado el pensamiento siguiente: 'El camino ordinario (por mayoritario) de salvación son las religiones no cristianas, mientras que la Iglesia sería el camino extraordinario de salvación'. Atribuido tanto a Rahner como a Küng.

Esta tesis de los "cristianos anónimos" se criticó fuertemente desde su aparición. Al fin, el 
inclusivismo, como el exclusivismo, mantienen el carácter absoluto del cristianismo. El inclusivismo no deja de ser un exclusivismo suavizado. Y una falta de respeto a la identidad de los demás.

\section{Pluralismo / Teocentrismo: Nuevo Paradigma}

No quiere decir -sólo- "pluralidad de religiones", sino que expresa la posición teológica que afirma que todas las religiones participan de la salvación de Dios, cada una a su modo, y autónomamente. Es decir, no hay una religión que esté en el centro mismo del universo religioso. En el centro sólo está Dios. Las religiones giran en torno a Dios, como los planetas en torno al sol. También el cristianismo.

En esta nueva perspectiva, cosmovisión o paradigma pluralista, se cuestiona al cristocentrismo tradicional, "ya que en el teocentrismo, Dios, y no Jesucristo, se convierte en el centro del designio salvífico de la humanidad. En este cambio se cuestiona la unicidad de Jesucristo como único mediador entre Dios y la humanidad" (Teixeira, 1999: 125).

El británico John Hick (www. johnhick.org.uk) es considerado como el más destacado representante del pluralismo teológico; el primero que lo manifestó y razonó con claridad. "Revolución copernicana" llama a este enfoque, siguiendo la alegoría del geocentrismo que pasa a heliocentrismo.

Hick presenta, tal vez, el mayor desafío teológico de la historia, porque supone un replanteamiento cualitativo y total: hay que desconstruir todo para volverlo a construir desde otro paradigma. Que Cristo no esté en el centro es sin duda el elemento más difícil de la posición pluralista. El carácter absoluto del cristianismo y la unicidad de Cristo como Salvador es lo que no puede afirmar el pluralismo, porque va contra su definición, razón por la que sus críticos lo consideran como una posición "no cristiana", fuera de la actual ortodoxia.

Hemos de considerar que el pluralismo reivindica una igualdad básica de las religiones, no un igualitarismo que las quiera hacer prácticamente idénticas.

Mucho mal le ha hecho al pluralismo teológico la acusación de "relativismo". El pluralismo afirma la relatividad de las formas religiosas, no el relativismo frente a las religiones. Una cosa es relatividad y otra es relativismo.

¿Cuánto tardará la Iglesia católica en aceptar la posición pluralista? ...

\section{El pluralismo es positivo y querido por Dios}

Durante 20 siglos, el pluralismo era un hecho, pero un hecho 
negativo, lamentable, no querido por Dios; tal vez simplemente tolerado, transitorio y llamado a desaparecer. Si no había desaparecido, sería por deficiencia de nuestro espíritu misionero.

Hoy, en la hora de la mundialización (globalización), las sensibilidades y actitudes han cambiado hacia la consideración positiva del pluralismo, movidas por la experiencia de la coexistencia plural, por la fuerza de los nuevos paradigmas. Y por los fundamentos teológicos básicos del mismo pluralismo:

\section{a. La universal voluntad salvífica de Dios para con todos los se- res humanos y todos los pue- blos (1Tim 2, 4 y Hch 4, 12).}

b. La sobreabundante riqueza y variedad de las automanifestaciones de Dios a la Humanidad.

Dios no puede estar atado a un clan, a un pueblo, a una cultura, a una religión. La inmensidad de un Dios que es Amor está más allá de todo eso y no es manipulable. Dios es pluralista, universal, de todos los pueblos...Por tanto,

\section{No hay pueblos 'elegidos'}

Según la visión clásica, Dios habría 'elegido' a un pueblo entre todos los pueblos. Es un concepto central en la Biblia. Todo gira en torno a él. Sin embargo, las investigaciones últimas concluyen en que la idea de la "elección" aparece también en las otras religiones. Nos remitimos al libro de Finguerman, Ariel. (2008). La elección de Israel. Estudio histórico comparado sobre la doctrina del "Pueblo elegido". Córdoba (España): Editorial El Almendro. -Y en editorial Abya Yala, Quito (Ecuador).

Pese a las manifestaciones bíblicas, hoy tiene más detractores que defensores. Por más argumentos que esgriman los defensores, se intuye que no tienen fundamento, repugnan a la nueva sensibilidad pluralista. Parece que el Dios universalista que lucha contra la desigualdad, no sería tan caprichoso, arbitrario y favoritista. En Dios "no hay acepción de personas"...ni de pueblos ni de religiones.

Knitter describe la evolución de la Iglesia en relación con las otras religiones de la siguiente manera:

- Durante la mayor parte de su historia, el cristianismo ha tenido una actitud hostil $>$ Cristo contra las religiones.

- Desde el Vaticano II > Cristo dentro de las religiones. Defensores: K. Rahner, E. Schillebeeckx...

- A fines del siglo $X X>$ Cristo por encima de las religiones, normativamente. Defensores: H. Küng, P. Schoonenberg... 
- Últimamente > Cristo con las otras religiones. Defensores: P. Knitter, R. Panikkar, A. Pieris...

- El cristianismo debería avanzar más allá del teocentrismo para llegar al "soteriocentrismo". Aunque es verdad que cualquier "-centrismo" corre el riesgo de volverse limitante. El misterio divino (Dios) sería el centro de la historia de la salvación y el punto de partida para el diálogo mutuo entre las religiones.

El fundamento y el mayor interés para cualquier valoración que se haga de las otras religiones no es su relación con la Iglesia (eclesiocentrismo), con Cristo (cristocentrismo) o incluso con Dios (teocentrismo); sino más bien qué es lo que llevan a cabo en pro de la salvación o bienestar de la humanidad [soteriocentrismo]. Tal enfoque implica que alli donde las religiones no compartan esa inquietud por el bienestar de la humanidad, se hace imposible el diálogo y hasta ni merece la pena (Knitter, 1986: 131).

\section{Pluralismo y Jesús de Nazaret}

Lo más grave de la ortodoxia del dogma cristológico milenario reside en que el Cristo allí presentado ha perdido la conexión con el Jesús histórico: es un Cristo sin
Reino. Lo cual se puede observar en el Símbolo Nicenoconstantinopolitano de nuestra fe: De la encarnación se pasa a la muerte y resurrección, sin resaltar la vida, la historia y el mensaje de Jesús de Nazaret.

La mayoría de las Cristologías clásicas posconciliares tratan el tema del pluralismo religioso, aunque no lo expliciten. Aparece al comentar las ACTITUDES de Jesús, novedosas, extrañas e incomprendidas en su tiempo: Se inauguraba el tiempo nuevo, el nuevo eón, la nueva historia; un nuevo paradigma religioso...encarnado, vivido. Veamos las principales actitudes, relacionadas con el pluralismo. (Seguimos la enumeración de Vigil, 2005: p. 114ss. Nos parece acertada e iluminadora):

\section{Actitud Teo-reinocéntrica}

El Dios del Reino y el Reino de Dios es la sola realidad doble que predicó y que pretendió Jesús. Indiscutiblemente fue el sueño, la causa, la utopía, el ideal, el centro de su vida. Apenas habló de sí mismo, y esto en función del Padre y del Reino. Lo único esencial que enseñó -en obras y palabras- fue ese único mensaje dual: Cómo es Dios, y su Proyecto (o su Plan o Reino o Reinado). 'El Reino de Dios y su justicia' (Mt 6, 33) es lo que debe ser buscado por encima de todo; lo 
demás 'vendrá por añadidura'...o puede esperar.

El paradigma pluralista es teocéntrico, a diferencia del exclusivismo e inclusivismo. En el lenguaje del evangelio de Jesús, Dios es siempre el "Dios del Reino", y el Reino es siempre el "Reino de Dios", de modo que teocentrismo y reinocentrismo se implican mutuamente.

\section{Actitud Macroecuménica}

Así comprende Jesús el Reinado de Dios. Porque el Reino es Vida, Verdad, Justicia, Paz, Gracia, Amor...Por eso, allí donde hay presencia de todas estas realidades, hay presencia del Reino. Donde se da el bien, ahí está el Reino. Jesús es optimista: a pesar de todo, hay mucho de bueno por el mundo. Su Padre hace salir el sol sobre justos y pecadores (Mt. 5, 45).

Jesús no es chauvinista. No piensa que 'sólo nosotros' o 'sólo los nuestros' estamos en el Reino. Le dice al gentil: "no estás lejos del Reino de Dios"; y al centurión y a la mujer cananea -ambos paganos: "no he encontrado tanta fe en Israel" (Mc. 12, 34; Mt 8, 10). Esa mirada universalista de Jesús y su espíritu pluralista se refleja más clara y extremosamente en la parábola del 'Juicio de las naciones' (Mt 25, 31 ss). En ella no cuenta la identidad o el cumplimiento 'religiosos'.
Sólo cuenta la práctica del amor y de la justicia.

\section{Actitud Teopráxica}

Para Jesús, Dios no es una entelequia, una razón suprema, una teoría; ni una doctrina o una ortodoxia. Siguiendo la mejor tradición de los profetas (Jer. 22, 16), Jesús proclama que Dios quiere la práctica de la justicia y del amor. Fuera de ello, la religión, reducida a confesión oral, a ortodoxia doctrinal o a liturgias rituales, se hace inútil: "no el que me diga 'Señor, Señor', sino el que haga la voluntad de mi Padre" (Mt. 7, 21). La religión es 'teopraxis', puesta en práctica de la voluntad de Dios. Este sería un criterio para medir la veracidad de toda religión.

\section{Actitud Anticúltica}

La praxis del amor y de la justicia está por encima incluso del culto y de las prácticas religiosas.

Este carácter anticúltico fue ya conocido en la tradición del A.T. Los profetas han sido, en general, poco amigos de los sacerdotes y de los templos.

Jesús es una persona profundamente religiosa, pero no 'religiosista'. No era un hombre del Templo, obsesionado por el cumplimiento de las leyes, reglas o prohibiciones. Tiene una visión y una práctica de 
la religión que rompe los moldes de la religión establecida en su sociedad. Es un laico. Y algunas de sus parábolas son ciertamente anticlericales, dejando al personal religioso en muy mal lugar. Particularmente la parábola del buen samaritano (Lc 10, 25-37).

\section{Actitud No-eclesiocéntrica}

Actitud evidente y "anacrónica” en su denominación, pero muy significativa: Jesús fue reinocéntrico, como hemos visto; no eclesiocéntrico. "Tampoco fue 'eclesiástico'; nunca pensó fundar una Iglesia, y hasta se puede decir que, de alguna manera, su mensaje central implicaba la superación de lo que es una Iglesia institucional... Que Jesús no quiso fundar una Iglesia es un dato poseído pacíficamente dentro de la exégesis y la teología desde hace décadas, pero un dato que cuesta que llegue a calar en la conciencia de las masas cristianas. Para muchas personas cristianas "normales", en efecto, Jesús sigue siendo el 'fundador' de la Iglesia en todo el sentido de la palabra; más aún, vino para fundar la Iglesia" (Vigil, 2005: 119).

De hecho hay un solo texto en los evangelios en el que se habla propiamente de la "Iglesia": Mt 16, 18. Pero la investigación hoy es unánime en el reconocimiento de que el pasaje de Mateo tiene origen postpascual y no es del Jesús histórico.

Durante casi veinte siglos, la Iglesia misma ha estado confundida pensando que la fundación de la Iglesia fue una fundación históricojurídica, que se habría dado en un momento determinado de la vida de Jesús, y de la que Jesús tuvo plena conciencia y voluntad; que dejó bien determinada su organización, su estructura, sus ministerios principales, los sacramentos, etc. Todo ello establecido por Jesús y, por tanto, no sólo serían la voluntad única de Dios, sino que serían también inmutables e irreformables.

- Así es imposible el diálogo interreligioso.

\section{¿Más allá de la "religión”?}

Desde el Modernismo teológico se viene sospechando si la novedad de Jesús consistiría en la abolición de todas las religiones, de forma que podamos redescubrir nuestra relación con Dios en el mismo proceso de la creación y de la vida, en la historia. Todos lo hemos pensado alguna vez.

Jesús es más grande que el cristianismo. Su palabra y su actitud crítica para con la religión, sus fuertes insinuaciones, apuntan hacia una religión más allá de la religión. Se enfrenta a las instituciones religiosas, y expresa claramente que quiere liberar al ser humano de ese 
tipo de relación con Dios. Quiere que se adore a Dios "en espíritu y en verdad", sin atarse a tiempos o lugares sagrados, con una moral de libertad: "El sábado es para el ser humano y no el ser humano para el sábado" (Mc. 2, 27). Lo principal es la vida misma.

“Sería, pues, una herejía decir que lo que Jesús pretendió fue hacer tomar conciencia a la gente de que la misma religión, sobre todo en sus aspectos legislativos, culturales y rituales, acaba siendo una esclavitad, mientras que la fe verdadera, la verdadera espiritualidad, tendría que ser la gran liberación de todo lo que oprime a las conciencias? Él quería otro tipo de relación del ser humano con Dios..." (Arias, 2001: 136).

"Jesús no llamó a una nueva religión, sino a la vida", repetía Dietrich Bonhoeffer. (Citado por Arias, 2001: 135. Y por otros autores).

¿Será verdad la relevante invitación de Jesús a superar la religión, a la superación de todas las "religiones"?

\section{Pluralismo y el Cristo de la fe}

El dogma cristológico es el nudo gordiano del pluralismo. (Dejamos su tratamiento para otro trabajo).
El cristianismo dice que su 'fundador', Jesús de Nazaret, es Dios mismo, la segunda persona de la Santísima Trinidad, que se ha encarnado en la Humanidad para dar a conocer la verdad y traer la salvación.

Esta afirmación dogmática sobre Jesús es el núcleo mismo del cristianismo, mantenido durante casi los dos milenios de su historia en una conciencia clara de exclusivismo, el cual sólo hace unos 40 años ha derivado en inclusivismo, $y$ que ahora se resiste a dar el paso a la aceptación del pluralismo, como paradigma superador del exclusivismo y del inclusivismo.

- El problema no viene del Jesús histórico, sino del Cristo de la fe edificado por la dogmática cristiana, ya desde las primeras reflexiones postpascuales de las comunidades paulinas y apostólicas y, sobre todo, desde el constantinismo y los primeros concilios ecuménicos.

La Iglesia ha vivido prácticamente toda su historia creyendo que eran históricas las palabras que Juan puso en boca de Jesús, que afirmaban su identidad con el Padre, su consciente y proclamada divinidad, etc. Jesús nunca fue cristocéntrico, sino teocéntrico y reinocéntrico -como acabamos de ver. Jesús nunca predicó nuestra 
dogmática cristológica. De "mensajero" de la Buena Nueva fue convertido él mismo en "mensaje" cristiano. El Cristo todopoderoso, Pantócrator, sustituto de Júpiter en el Panteón romano, se constituyó poco a poco en mensaje de la Iglesia cristiana y desplazó también poco a poco el mensaje subversivo de Jesús, lo cual permitió a la Iglesia asumir el papel de religión oficial del imperio que había ejecutado a su 'fundador'.

Se ha dicho con frecuencia que los cuatro grandes concilios -llamados «ecuménicos»- de la antigüedad sustituyeron en la Iglesia cristiana a los cuatro evangelios... Hoy, afortunadamente, hace tiempo que recuperamos los evangelios, pero el constructo teológico cristológico que en cierto sentido los sustituyó sigue ocupando el centro del cristianismo, como un enclave de fundamentalismo que se resiste a su estudio y reinterpretación, y mucho más a su reformulación. "La doctrina de Nicea recurre a la Escritura, pero la utiliza de una forma que hoy no es aceptable" ( $R$. Haight. Citado por Vigil, 2005: p. 180).

Esta pieza esencial e intocable del cristianismo es la que está crujiendo, presionada por el nuevo paradigma del pluralismo religioso, por la consiguiente transformación de las perspectivas teológicas, por las nuevas cosmovisiones del sentido religioso, por el diálogo interreligioso, por las nuevas sensibilidades de la humanidad, por su sentido de autonomía personal racional, etc.

Esta pretensión "lógica" del pluralismo religioso allanaría la mayoría de los obstáculos del diálogo intra - y extraeclesial. Tal vez necesite más estudios y justificaciones, si bien cada día aparecen nuevos trabajos y alusiones a ella. Acaso nos falta perder el miedo, espíritu abierto y fe. - Se aprende a dialogar, dialogando.

\section{Algunas conclusiones}

- ¿Es posible contagiar la fe en este mundo nuevo que está naciendo, sin conocerlo bien y sin comprenderlo desde dentro? ¿Es posible facilitar el acceso al Evangelio ignorando el pensamiento, los sentimientos y el lenguaje de los hombres y mujeres de nuestro tiempo? ¿No es un error responder a los retos de hoy con estrategias de ayer?

- La visión cultural y religiosa heredada por nuestra generación estaba construida desde y sobre una epistemología que hoy ya desapareció. Las personas y las sociedades, cuyos valores y sentido de vida está expresado en una epistemología distinta de la realmente vigente en la sociedad cultural 
real, viven una esquizofrenia psicológica y gnoseológica.

- Es urgente la «educación en los nuevos paradigmas», en todos los campos, y también, específicamente, en el campo religioso.

- Es necesario el paso sereno de un pluralismo religioso de hecho a uno de derecho.

Existimos en una cultura pluralista, o «pluralismo cultural», antes y además del pluralismo religioso. Por tanto aceptemos el pluralismo de derecho (Dios quiere la pluralidad).

- El ecumenismo y el diálogo interreligioso sólo serán útiles si previamente se realiza un "intra-diálogo".

- Todos los cristianos/as, desde los teólogos palaciegos hasta el más humilde de los catequistas, tienen el derecho y el deber de hacer avanzar a la comunidad cristiana comprendiendo e internalizando este nuevo paradigma teológico del pluralismo, el cual se impone por su evidencia. Es inevitable, positivo y querido por Dios.

- Es exigencia de los nuevos paradigmas el abandonar ya el inclusivismo y aceptar el pluralismo de las vías de salvación, igual que fue posible superar el exclusivismo que el cristianismo profesó como dogma durante milenio y medio.

- Jesús de Nazaret, el olvidado del "Credo", sigue siendo el mejor modelo para el cristianismo. Por sus actitudes. También modelo para el diálogo intra- y extraeclesial.

- El tiempo de las misiones clásicas ha pasado. La misión proselitista no se funda en Jesús. Los textos neotestamentarios que se aducen a su favor, ni son palabras de Jesús ni tienen fundamento histórico. La misión de la misión no es otra que la extensión del amor en colaboración, el compartir el diálogo interreligioso, la petición de perdón y la "conversión al Reino de Dios" (Vigil, 2004. Relat: 351).

- Parece que el pluralismo teológico hará imprescindible el re-visar y re-pensar totalmente la cristología y, por tanto, los fundamentos actuales del cristianismo. Kairós llovido del cielo para el diálogo intraeclesial y ecuménico; y para el diálogo interreligioso con "odres nuevos". 


\section{Bibliografía}

Arias, J. (2001). Jesús, ese gran desconocido. Madrid: Maeva Ediciones.

ASETT. Carta de la ASETT, en Alternativas, $\mathrm{n}^{\circ} 35$, enero - junio 2008, pp. 249 -252 .

Barros, M. Moradas del viento en los caminos humanos. Para una teología de la hierodiversidad, en Concilium, $\mathrm{n}^{\circ} 319$, febrero 2007, pp. $59-67$.

Boff, L. (2000). La dignidad de la Tierra. La emergencia de un nuevo paradigma. Madrid: Trotta.

Boff, L. (2003). La voz del arco iris. Madrid: Trotta.

Capra, F. (1985). El punto crucial. Ciencia, sociedad y cultura naciente. Barcelona: Integral Ed.

Capra, F. $\left(2003^{6}\right)$. El Tao de la Física. Málaga (España): Ed. Sirio, S.A.

Casaldáliga, P. y Vigil, J.M. (1992). Espiritualidad de la Liberación. Santander: Sal Terrae.

Comisión Teológica Internacional (1998): Documentos 1969 -1996. Veinticinco años de servicio a la teología de la Iglesia. Edición preparada por Cándido Pozo, S.I., con Prólogo del Card. Joseph Ratzinger. Madrid: BAC.

Congregación para la Doctrina de la Fe. (2001). Declaración Dominus Iesus (6 agosto 2000). Guatemala: Ediciones San Pablo.

Denzinger, E. (1963). El Magisterio de la Iglesia. Manual de los símbolos, definiciones y declaraciones de la Iglesia en materia de fe y costumbres. Barcelona: Herder.
Documentos del Concilio Vaticano II: Gaudium et Spes, Lumen Gentium; Nostra Aetate, Unitatis Redintegratio, Ad Gentes. 1964.

Dupuis, J. (2000). Hacia una teología cristiana del pluralismo religioso. Santander: Sal Terrae.

Finguerman, A. (2008). La elección de Israel. Estudio histórico comparado sobre la doctrina del "Pueblo elegido". Córdoba (España): Editorial El Almendro.

Hick, J. (2004). La metáfora del Dios encarnado. Quito: Abya-Yala.

Knitter, P. La teología de las religiones en el pensamiento católico, en Concilium, $\mathrm{n}^{\circ}$ 203, enero 1986, pp. 123 - 134.

Martín Velasco, J. (19983). El malestar religioso de nuestra cultura. Madrid: San Pablo.

Morin, E. (2003). La mente bien ordenada. Barcelona: Seix Barral.

Nemeth-Baumgartner,A. (1994). Macrometanoia. Un nuevo orden. Una nueva civilización... Santiago-Chile: Ed. Sudamericana.

Pío IX: Alocución Singulari quadam (09 / 12 / 1854).

V Conferencia General del Episcopado Latinoamericano y del Caribe. (13-31 / 05 / 2007). Documento Conclusivo. Aparecida.

Schillebeeckx, E. (1994). Soy un teólogo feliz. Madrid: Sociedad de Educación Atenas.

Swimme, B. (1998²). El universo es un dragón verde. Santiago de Chile: Sello Azul.

Teixeira, F. Nuevos paradigmas resultantes del diálogo interreligioso, en Fabri, M. 
(1999). Teología y nuevos paradigmas. Bilbao: Mensajero.

Tamayo-Acosta, J.J. (2004²). Nuevo Paradigma Teológico. Madrid: Trotta.

Torres Queiruga, A. (2008). Repensar la Revelación. La Revelación Divina en la Realización Humana. Madrid: Trotta.

Torres Queiruga, A. (1992). El diálogo de las religiones. Santander: Sal Terrae.
Vigil, J.M. (2005). Teología del Pluralismo Religioso. Curso Sistemático de Teología Popular. Quito: Abya Yala.

< www.servicioskoinonia.org/relat/ >

$<$ www.Eclesalia.net >

$<$ www.zenit.org $>$ 
